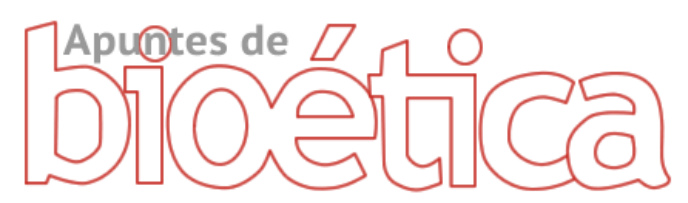

https://doi.org/10.35383/apuntes.v1i1.191

\title{
La persona y la Corte Interamericana de Derechos Humanos
}

\author{
Silvia Johanna Alburqueque Uceda ${ }^{1}$
}

\section{INFORMACIÓN DEL ARTÍCULO RESUMEN}

Recibido el 27 de setiembre de 2018

Aceptado el 20 de noviembre de 2018

\section{Palabras claves:}

Corte Interamericana de Derechos Humanos

Persona, identidad

Derecho a la vida

Ideología
La Corte Interamericana de Derechos Humanos (Corte IDH) ha tenido, dentro del Sistema Interamericano de Derechos Humanos, la importante función de garantizar el respeto y protección de los derechos humanos de las personas frente a una posible actuación arbitraria de los Estados, que lesione, impida u obstaculice el ejercicio de los mismos. Es así que, la actuación de la Corte ha sido por muchos años, un instrumento fundamental para una correcta aplicación de los derechos plasmados en la Convención, que ha tenido como centro de actuación, la persona humana. Sin embargo, en los últimos años, la Corte IDH ha dado un giro bastante notorio en relación a la interpretación de los derechos que la Convención define y defiende, a través de sentencias en las que ha llegado a trastocar el núcleo de protección de derechos básicos y elementales, como el derecho a la vida, a la identidad, a la no discriminación, que, de acuerdo con nuestro análisis, afectaría, principalmente, el desarrollo de la persona desde una visión objetiva e integral, con la aparición de serias consecuencias, que expondrían a la Corte a dejar de ser un mecanismo importante de protección jurídica para pasar a ser un mecanismo de expansión de ideologías contrarias a la propia persona.

${ }^{1}$ Abogada por la Pontificia Universidad Católica del Perú, magister en Ciencias del Matrimonio y la Familia por el Instituto Po ntificio Teológico Juan Pablo II de Roma. Miembro de la Comisión Consultiva de Derecho Canónico del Colegio de Abogados de Lima. Actualmente se desempeña como asesora legal de la Diócesis de Carabayllo. Email: siavanti@hotmail.com ORCID: https://orcid.org/ 0000-0003-2490-0911 


\section{The person and the Inter-American Court of Human Rights}

ABSTRACT

Keywords:

KInter-American Court of Human Rights

Person,

Identity

Right to life

Ideology.
The Inter-American Court of Human Rights (Inter-American Court of Human Rights) has had, within the Inter-American Human Rights System, the important function of guaranteeing respect and protection of human rights of individuals in the face of possible arbitrary action by the States, which may injure, prevent or hinder the exercise of them. Thus, the Court's performance has been for many years, a fundamental instrument for the correct application of the rights embodied in the Convention, which has had as its center of action, the human person. However, in recent years, the Court has taken a quite noticeable turn in relation to the interpretation of the rights that the Convention defines and defends, through sentences in which it has come to disrupt the core of protection of basic and elementary rights, as the right to life, to identity, to non-discrimination, which, according to our analysis, would affect, mainly, the person's development from an objective and integral view, with the emergence of serious consequences, that would expose the Court to cease being an important mechanism of legal protection to become a mechanism of expansion of ideologies contrary to the person itself.

\section{Introducción}

El 21 de enero de 1981, el Perú presentó en la Secretaría General de la Organización de Estados Americanos (OEA), el instrumento de reconocimiento de la competencia de la Comisión Interamericana de Derechos Humanos (CIDH), así como de la Corte Interamericana de Derechos Humanos (en adelante, Corte, Corte Interamericana o Corte IDH), de acuerdo con los artículos 45 y 62 de la Convención Americana de Derechos Humanos $(\mathrm{CADH})^{2}$-también conocida como Pacto de San José- para conocer sobre las materias relativas al cumplimiento de los

\footnotetext{
2 Declaraciones/Reservas/Denuncias/Retiros en referencia a la Convención Americana de Derechos Humanos, obtenido en https://www.oas.org/dil/esp/tratados_B-

32_Convencion_Americana_sobre_Derechos_Humanos_firmas.htm
}

compromisos asumidos por los Estados parte de la CADH, establecido en su artículo 33.

Dentro de este sistema interamericano de protección de los Derechos Humanos, la Corte IDH ha tenido un rol importante a través de sus funciones ${ }^{3}$, ya que "puede y debe contribuir a resolver situaciones violatorias de derechos humanos; así como esclarecer los contenidos

\footnotetext{
3 La Corte IDH tiene dos formas de actuación frente a los Estados: contenciosa y consultiva.

El art. 62.3 de la CADH establece que "La Corte tiene competencia para conocer de cualquier caso relativo a la interpretación y aplicación de las disposiciones de esta Convención que le sea sometido, siempre que los Estados Partes en el caso hayan reconocido o reconozcan dicha competencia, ora por declaración especial, como se indica en los incisos anteriores, ora por convención especial.

El art. 64.1 de la CADH establece que "Los Estados miembros de la Organización podrán consultar a la Corte acerca de la interpretación de esta Convención o de otros tratados concernientes a la protección de los derechos humanos en los Estados americanos. (...)"
} 
jurídicos de la Convención" (Melgar, 2016, p.96). Sin embargo, en los últimos años, estas facultades han sido cuestionadas, principalmente debido a la forma en que la Corte ha utilizado los medios de interpretación jurídica, para fundamentar cambios importantes en la forma de entender derechos fundamentales, con especial relevancia para los países miembros de la comunidad americana. Una de las formas de interpretación más usada y cuestionada, ha sido la interpretación evolutiva de derechos, que sostiene que la interpretación de los tratados debe hacerse conforme a la evolución de los tiempos (De Jesús y Oviedo, 2016). Aunque, como afirma Díaz (2013), la interpretación evolutiva solo puede darse cuando existan términos evolutivos o abiertos al momento de enunciar un derecho particular y cuando dicha interpretación no afirme lo contrario de lo que expresa la norma, como ha venido sucediendo en los pronunciamientos últimos.

Nos referimos especialmente a los casos Artavia Murillo y otros vs. Costa Rica y Atala Riffo y niñas vs. Chile, relacionados directamente con derechos básicos y elementales de las personas, pudiendo llegar a evidenciarse una intervención de intereses políticos e ideológicos provenientes de países considerados más desarrollados y de organismos internacionales con agendas establecidas, que promueven reformas en el contenido de ciertos derechos, a través de interpretaciones direccionadas, carentes de una justificación objetiva, que pueden ser restrictivas de derechos, en algunos $\operatorname{casos}^{4}$, y bastante amplias en otros ${ }^{5}$, con una clara repercusión, en

\footnotetext{
${ }^{4}$ Párrafo 264 - Sentencia Artavia Murillo y otros vs. Costa Rica: "La Corte ha utilizado los diversos métodos de interpretación, los cuales han llevado a resultados coincidentes en el sentido de que el embrión no puede ser entendido como persona para efectos del artículo 4.1 de la Convención Americana. (...) Además, es posible concluir de las palabras "en general" que la protección del derecho a la vida con arreglo a dicha disposición no es absoluta, sino es gradual e incremental según su desarrollo, debido a que no constituye un deber absoluto e incondicional, sino que implica entender la procedencia de excepciones a la regla general". (la cursiva y resaltado es nuestro)

${ }^{5}$ Párrafo 110 - Sentencia Atala Riffo y niñas vs. Chile: “(...) al ser, en abstracto, el "interés superior del niño" un fin legítimo, la sola referencia al
}

la forma de comprensión de la persona, de sus derechos y por ende, en su protección integral.

Este cambio de apreciación dado por los jueces interamericanos ha sorprendido a muchos por el cambio radical de apreciación sobre derechos básicos de la persona que los Estados buscaban proteger claramente y que justificaban el sometimiento voluntario a la competencia de la Corte. Sin embargo, este cambio obedecería, principalmente, a una nueva forma de pensamiento orientada desde organismos internacionales que buscarían introducir "nuevos derechos" basados, sobre todo, en criterios de autonomía y autodeterminación, que convierten deseos y necesidades en derechos con las consecuencias negativas de dejar desprotegida a la persona desde su etapa más incipiente y afectar su comprensión como tal.

Para la redacción del presente trabajo hemos considerado hacer un breve análisis sobre la persona, teniendo en cuenta la actuación y fundamentación de los jueces en el caso Artavia Murillo, que ha sido señalada de marcar un antes y un después en el tratamiento corriente que se le daba a la persona, con un posible sesgo ideológico que ha dejado de lado el aspecto objetivo y real de la misma. Por lo que, de forma breve y sencilla, a través del desarrollo de nuestros objetivos como son, establecer el concepto de persona e identificar los argumentos más relevantes de la sentencia mencionada en relación al tratamiento de la vida de la persona, podremos distinguir, quien es la persona en la Corte IDH.

\footnotetext{
mismo sin probar, en concreto, los riesgos o daños que podrían conllevar la orientación sexual de la madre para las niñas, no puede servir de medida idónea para la restricción de un derecho protegido como el de poder ejercer todos los derechos humanos sin discriminación alguna por la orientación sexual de la persona. El interés superior del niño no puede ser utilizado para amparar la discriminación en contra de la madre o el padre por la orientación sexual de cualquiera de ellos. (...)". (la cursiva y el resaltado es nuestro)
} 


\section{Metodología}

El presente trabajo de investigación es de tipo cualitativo, descriptivo e interpretativo, realizado a través de un análisis de la información de la bibliografía seleccionada en libros, artículos, sentencias, a fin de plantear nuestra pregunta de investigación sobre cuál es el concepto que tiene la Corte IDH sobre la persona. A partir del análisis realizado, hemos podido enriquecer tanto nuestras preguntas como las respuestas obtenidas y evidenciar sus consecuencias; haciendo de la acción indagatoria, de acuerdo a lo planteado por Hernández (2014), un proceso dinámico y circular entre los hechos y su interpretación. Asimismo, sostiene el autor que en el abordaje metodológico de la investigación cualitativa se dan de manera simultánea la muestra, la recolección de datos y el análisis; en cuanto a la recolección de datos los instrumentos empleados han sido: las fichas bibliográficas, a fin de seleccionar temas y autores; fichas de resumen para sintetizar ideas de acuerdo a temas; fichas textuales a fin de mantener la esencia de la idea de un autor y la búsqueda en internet de artículos de revistas confiables. La técnica usada para la recolección de datos ha sido básicamente la revisión de documentos y el análisis de toda la información obtenida, a fin de llegar a establecer la situación real y actual de nuestro objeto de estudio (Bernal, 2010) y corroborar nuestros objetivos.

Finalmente, los criterios éticos presentes en nuestro trabajo son el respeto a la persona, la búsqueda del bien común y la justicia, y la protección de la dignidad de la persona; los mismos que son acompañados de criterios de rigor científico confiables que dan al trabajo relevancia académica.

\section{Resultados, análisis y discusión}

1.- Acercamiento a la realidad de la persona humana desde una visión integral

El concepto de persona que buscamos destacar en el presente trabajo lo tomamos de Sgreccia (2014) -quien ha sido el propulsor de la corriente bioética del personalismo ontológico, el mismo que utiliza como criterio de valoración ético jurídica, la dignidad y el valor absoluto de la persona-; para quien la persona es aquella que se explica como la unidad intrínseca de cuerpo y espíritu y que, por lo tanto, posee un carácter espiritual, intelectivo y moral. A pesar de que a lo largo de la historia el concepto de persona ha ido variando ${ }^{6}$, la importancia de establecerlo tiene implicancias para la actuación en temas éticos, bioéticos y jurídicos, ya que de acuerdo a lo expresado por Palazzani (1996), su definición determinará el equilibrio en el actuar de la propia persona y de los demás frente a ella; donde lo lícito vendría a ser todo aquello que no dañe el valor y los derechos de las personas y lo ilícito aquello que así lo hiciere; como por ejemplo dentro de situaciones de intervención sobre la vida humana, difíciles de afrontar para la ética y el derecho, tales como: clonación, destrucción y experimentación con embriones humanos, ingeniería genética, fecundación artificial, maternidad subrogada, sustitución de funciones vitales, técnicas de reanimación, trasplantes, control y programación de la muerte, diagnóstico prenatal, entre otros.

El concepto de persona, al igual que el de dignidad, muy ligado a ella, no ha sido un concepto pacífico, ya que a lo largo de la historia ha tenido diferentes acepciones y formas de acercamiento; sin embargo, la persona como realidad es una sola que puede ser abordada desde diversos ángulos. Por ello, como señala

\footnotetext{
${ }^{6}$ Para un alcance sobre los antecedentes del concepto de persona, véase la Parte I - Génesis del concepto, del libro de AMENGUAL, G. (2015). La persona humana. El debate sobre su concepto, Madrid, España: Síntesis.
} 
Sgreccia (2014) lo importante será "definir a la persona en su realidad constitutiva, más allá de la misma conciencia que todos los individuos humanos puedan tener de ella y más allá de las capacidades expresivas logradas por cada personalidad concreta" (p.132). Por lo que utilizaremos el lente biológico y antropológico, para finalmente establecer su estatus jurídico.

Desde lo biológico, ámbito científico y verificable, hablaremos del ser humano, perteneciente a la especie homo sapiens, cuyo inicio de vida coincide con la fertilización entre dos gametos femenino y masculino que conocemos como fecundación. Herranz (2013) señala que "en la fecundación, el nuevo ser, al heredar de sus progenitores su propio y nuevo genoma (...) adquiere su identidad biológica como individuo concreto" (p.71), el mismo que seguirá una trayectoria de crecimiento y desarrollo propia (autónoma) que se prolongará de manera continua y ordenada en la vida postnatal (Herranz, 2013). Al respecto, De La Fuente (2016) sostiene que esta realidad biológica es aceptada de forma mayoritaria aun por defensores del mal llamado derecho al aborto, como Peter Singer, filósofo utilitarista australiano, que ha señalado no tener dudas sobre el hecho que la vida humana comienza en el momento de la concepción, aun cuando posteriormente hace un reduccionismo cualitativo de la persona. Por ello, si bien el evento de la fecundación todavía mantiene una vigencia fuerte en el campo científico, sostiene Herranz (2013) que "el problema no reside propiamente en la biología descriptiva de la fecundación, sino en la interpretación de los hechos observados" (p.74). Lo señalado anteriormente se evidencia, por ejemplo, con las técnicas contraceptivas y de fecundación artificial donde se ha tratado de invalidar la fecundación como inicio de la vida del ser humano, reduciéndola a eslabón de un proceso biológico, indiferenciado de otros (Herranz, 2013). En nuestra opinión esto correspondería a una necesidad de justificar estas prácticas sin que entren en el debate ético y jurídico, por los grandes intereses económicos que representan, acordes con una visión individualista y utilitarista; por lo que, ante la posible relativización del valor biológico de la fecundación, los datos proporcionados por la ciencia tendrán que ser contrastados con otros aspectos de estudio de la persona como el antropológico.

El punto de vista antropológico de la persona, considerando la realidad biológica, nos propone responder a la siguiente pregunta: ies todo ser humano una persona? Lo cual nos lleva a hacernos también la necesaria pregunta: entonces, ¿quién es la persona? La respuesta puede ser enfocada desde dos visiones: la visión sustancialista o personalista -entendida como la visión tradicional- hasta la aparición de la visión funcionalista concebida en los años 70's con las respectivas consecuencias que de ella se han derivado (Di Pietro, 2008). A través de estas dos visiones se determinará la existencia o de una identidad natural o de una identidad dada o creada de acuerdo a parámetros establecidos entre la persona y el ser humano.

Para la visión funcionalista, el término persona indica un concepto abstracto, definido por un elenco de propiedades y funciones que no pertenecen necesariamente al ser humano sino a cualquier otro ser que demuestre poseerlas (Di Pietro, 2008). Possenti (2013) anota entre estas cualidades o funciones que determinarían la presencia del estatuto personal: la libertad, la autodeterminación, la capacidad de acción, la actividad psíquica, la conciencia, la autoconciencia, la responsabilidad, la memoria, entre otras. A la luz de esta visión, se cobijan teorías basadas en características biológicas o psico-sociales, en las que el ser humano no se identifica de forma natural con la persona. Entre las teorías de la visión funcionalista destacan: la teoría de la individualidad, la teoría de la 
implantación o relacionalidad, teoría de la presencia del sistema nervioso central o de la sensibilidad, la teoría de la formación de la corteza cerebral o de la racionalidad, la aparición del sistema nervioso central, la teoría del reconocimiento sustitutivo, la teoría de la intención de procrear y las teorías multifactoriales (Di Pietro, 2008; Palazzani, 1996). Un ejemplo de ello, son las tres categorías de individuos, producto de la relación ser humano - persona, establecidas por Singer: los animales personas, los seres humanos personas y los seres humanos no personas (De La Fuente, 2016). En esta última categoría entrarían aquellos seres humanos más indefensos como los embriones, fetos, discapacitados mentales o físicos, niños pequeños, privados de conciencia, en coma, enfermos terminales, etc., que debieran ser los principales sujetos de protección de un Estado de derecho.

Por el contrario, la visión sustancialista o personalista afirma que la persona es un sujeto individual, sustancial, dotado de espiritualidad y por tanto intrínsecamente capaz de intencionalidad, relacionalidad, interioridad, autodominio, libertad (Di Pietro, 2008). Así tenemos que, a partir de esta visión, la persona es el centro de unidad material y espiritual donde recaen todas estas características y no la expresión de una o la suma de todas. Possenti (2013) dirá al respecto que la persona es todas estas cosas juntas, que encuentran un núcleo último de apoyo en su acto de ser sustancial, único y unitario. La persona así concebida se diferenciará siempre del resto de los seres vivos, en su esencia, en su ser propio, que no es un proceso, sino que responde a un evento o acto instantáneo que la establece como tal desde el inicio hasta el final de su vida, que se situaría en la fecundación (Di Pietro, 2008), considerando que también "antropológicamente, es el inicio de un nuevo y original cuerpo humano" (De La Fuente, 2016, p.322). Así, bajo esta visión podremos afirmar a la pregunta inicial que todo ser humano es persona.

Por último, llegamos al aspecto jurídico. Al respecto, Hervada (1999) recalca que, si bien el concepto ontológico y jurídico de persona son conceptos distintos, pues uno proviene de la filosofía y otro del derecho, la realidad sobre la que están referidos es la misma, estando el concepto jurídico inmerso en el ontológico, pues el hombre posee una juridicidad natural que lo lleva a relacionarse jurídicamente con los demás; reafirmando que todo hombre es por naturaleza sujeto de derecho. Comprendida la persona como sujeto de derecho, es la protagonista del orden social y jurídico, titular de derechos y deberes, cuya determinación será importante para el sistema jurídico, a fin de no llegar a situaciones injustas donde se le nieguen derechos inherentes a ella.

Nuevamente nos encontraremos con dos posiciones resaltantes al respecto: aquella para la cual la relación entre las realidades de persona ser humano - sujeto de derecho no se identifican entre sí, que correspondería a una dimensión jurídica positiva, por la que ningún hombre sería propiamente una persona, sino solo aquellos a los que la ley positiva se los concediera (Hervada, 1999). Por el contrario, aquella posición que sostiene que las realidades mencionadas sí son identificables entre sí, correspondería a una visión iusnaturalista del derecho, por la que los hombres son por naturaleza, sujetos de derecho y permiten la existencia del fenómeno jurídico en sí (Hervada, 1999). Esta comprensión iusnaturalista de la persona es la que se evidencia en la CADH cuando establece en su artículo 1.2 que, para efectos de la Convención, persona es todo ser humano. Así tenemos que, el derecho a la vida, a la identidad y a la libertad de las personas que se encuentran plasmados en la Convención, responden a lo que les es debido por su naturaleza humana, es decir, lo justo, "objeto de la virtud de la justicia (...) objeto de la 
ciencia práctica del jurista" (Chávez-Fernández, 2014, p.23); y no algo que se haya constituido para ellas de forma extrínseca como expresión de la autonomía personal o del consenso. En conclusión, vemos que a pesar de la existencia de diferentes visiones que existen sobre la persona, aquellas que plantean la identidad entre ser humano y persona, se acercan a la verdad no solo teórica sino práctica y real sobre quién es la persona, permitiendo que el derecho pueda brindarle una protección integral y sobre todo asegurando la propia existencia del sistema jurídico.

\section{2.- Aproximaciones al caso Artavia Murillo y otros vs. Costa Rica: la vida de la persona.}

La Corte Interamericana, en muchos casos, determinante para tutela y correcta interpretación y aplicación de las disposiciones de la Convención ante la posible vulneración por parte de los Estados miembros, tiene incoada a cada una de sus funciones la importante tarea de garantizar y restablecer el reconocimiento del libre ejercicio de los derechos vulnerados de toda persona, sin discriminación alguna. Es por ello que la Corte IDH, como órgano jurisdiccional ${ }^{7}$, goza de autonomía para el ejercicio de sus funciones, a fin de que lo resuelto por los jueces sea realmente una puesta en práctica de la justicia para las personas afectadas. Sin embargo, ésta no ha estado exenta de cambios importantes en cuanto a la forma de interpretación de determinados derechos, así como de aquellos a quienes debe proteger y que se encuentran en un estado de mayor de vulnerabilidad, ya sea por razones de índole social, política, económica, física, entre otras.

\footnotetext{
${ }^{7}$ De acuerdo a lo expresado por Melgar (2016), si bien la Corte IDH es un órgano jurisdiccional internacional, no actúa como una cuarta instancia, sino que su actuación es de naturaleza subsidiaria, ayudando a los países a velar por la protección de los derechos de sus ciudadanos, promoviendo la integridad del sistema nacional e internacional.
}

La sentencia Artavia Murillo ha llamado profundamente la atención de juristas, filósofos, biólogos, y de la opinión pública en general tanto de los grupos defensores de la vida del ser humano desde sus primeros estadíos hasta el final, como de los grupos abortistas que han visto en esta sentencia una puerta abierta no solo para la cosificación de embriones, sino la excusa para la promoción del aborto como parte de los derechos sexuales y reproductivos, al encontrarse con un concepto de vida relativizado, como se verá a continuación.

\section{La vida de la persona en el Caso Artavia Murillo y otros vs. Costa Rica}

El derecho fundamental de todo ser humano, base para el ejercicio de los demás derechos y deberes es el derecho a la vida; por ello su protección no debe ser restrictiva sino por el contrario, cabe hacer una interpretación amplia del mismo (De Jesús y Oviedo, 2016). Así lo había entendido la Corte como fiel guardián de lo establecido por la CADH en su artículo 4.1, sobre el derecho a la vida, señalando que "Toda persona tiene derecho a que se respete su vida. Este derecho estará protegido por la ley $y$, en general, a partir del momento de la concepción. Nadie puede ser privado de la vida arbitrariamente $^{\prime 8}$.

Sin embargo, el panorama se volvería adverso para el ser humano en su inicio de vida, a partir de la sentencia del caso Artavia Murillo, que se basó para fundamentar la fecundación y concepción como dos momentos diferentes, en la definición del diccionario de la Real Academia Española que no es de alcance científico; dejando de lado lo establecido en la mayoría de diccionarios de carácter científico, donde el

\footnotetext{
${ }^{8}$ La protección del sistema interamericano es una de las más sólidas y fuertes en relación a otros instrumentos como el Convenio Europeo de Derechos Humanos, la Carta Africana o el Pacto de los Derechos Civiles y Políticos, pues a diferencia de estos, incluye la protección desde el inicio de la vida, antes del nacimiento.
} 
término concepción se "identifica con fecundación, en algunos se identifica con todo el proceso que va desde la fecundación hasta la implantación, pero en ningún caso se equipara con la sola implantación (...) pues en la implantación no se crea nada nuevo" (Ramos, 2016, págs. 222-223). Asimismo, la sentencia toma en consideración, principalmente, el informe del perito Zegers ${ }^{9}$, quien a lo largo de sus informes estableció -además de que la concepción debía ser equiparada al momento de la implantación del embrión en el útero de la mujer- que ésta correspondería a un evento propio de la mujer al margen de la existencia del embrión (Párrafo 181 de la sentencia) ${ }^{10}$, lo cual es una afirmación errada, ya que la condición indispensable para hablar de un embarazo es la existencia del embrión, más allá de la presencia o no de los síntomas de éste (Ramos, 2016). Asimismo, la Corte también deja entrever que la defensa en favor de la vida del embrión, obedecería a aspectos subjetivos (morales o religiosos) sin dar razones de tal afirmación, por lo que habría que dejarlos de lado, según se puede observar en el Párrafo 185 de la sentencia:

(...) para la Corte es claro que hay concepciones que ven en los óvulos fecundados una vida humana plena. Algunos de estos planteamientos pueden ser asociados a concepciones que les confieren ciertos atributos metafísicos a los embriones. Estas concepciones no pueden justificar que se otorgue prevalencia a cierto tipo de literatura científica al momento de interpretar el alcance del derecho a la vida consagrado en la

\footnotetext{
${ }^{9}$ La actuación del perito Zegers-Hochschild, fue muy cuestionada por sus evidentes intereses económicos al haber dirigido centros de reproducción asistida y promover la práctica de la FIV. Véase el siguiente link: http://www.icmartivf.org/zegers-hochschild.html. Además, la Corte no estableció el por qué fue preferido frente a otros peritos que alegaron pruebas científicas en contrario y que identificaban la fecundación con la concepción como la unión del óvulo y espermatozoide.

${ }^{10}$ De acuerdo a lo señalado en la sentencia en el voto disidente del juez chileno Vio Grossi (ver acápite sobre interpretación sistemática e histórica), ésta afirmación llevaría a sostener que el concebido no tiene derecho per se a que se respete su vida, sino que dependería de la voluntad de la mujer embarazada el que quiera respetar ese derecho, lo cual abriría una puerta al debate sobre la legitimidad del aborto.
}

Convención Americana, pues ello implicaría imponer un tipo de creencias específicas a otras personas que no las comparten. (EI resaltado y la cursiva son nuestros)

Esta posición sobre la prohibición de utilizar argumentos metafísicos para la comprensión de la persona, según Silva (2016), queda contradicha con la valoración negativa que la Corte hace sobre la vida del embrión humano y la eliminación de su estatus jurídico de persona, donde evidencia una clara inclinación hacia pensamientos basados en modelos utilitaristas y liberales, que recoge de los argumentos propios de la jurisprudencia internacional y regional de sistemas ajenos al nuestro y hasta de documentos no vinculantes, que en vez de reforzar la posición de la $\mathrm{CADH}$, le han ayudado a reinterpretar derechos $y$ modificar su sentido original ${ }^{11}$.

De igual modo, Cianciardo (2016) afirma que respecto a la afirmación de que el embrión humano no sea persona:

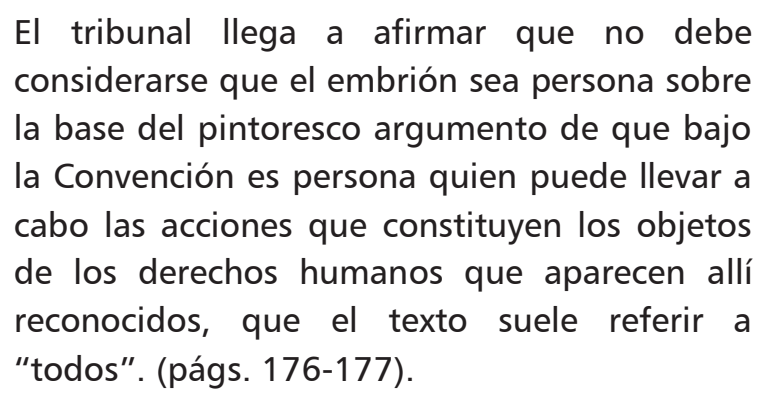

Así tenemos que, para la Corte el criterio para determinar si alguien es persona o no es la capacidad de ejercitar los derechos y no la pertenencia al género humano como lo afirma el artículo1.2 de la CADH; lo cual corresponde a un argumento falaz que identificaría el ejercicio de derechos con la titularidad de los mismos y ésta con la calificación de persona.

\footnotetext{
11 Para conocer los documentos citados por la Corte de manera selectiva para reforzar su posición, véase el acápite referido a la interpretación sistemática del artículo de De Jesús y Oviedo (2016) situado entre las págs.51-65.
} 
Sobre la Corte IDH, señala Ramos (2016), que todo esto pone en evidencia que "su estudio fue pobre y contiene varios errores importantes que terminan por oponerse no solo a la definición biológica del embrión, sino también contradice a la misma Convención Americana de Derechos Humanos" (pp.219-220), ya que existen sentencias anteriores en las que se reconoce a los niños por nacer como personas titulares de derechos, en las que se les nombra como niños, hijos, bebés; y en las que se refiere a los abortos inducidos como actos de barbarie (De Jesús y Oviedo, 2016). Por lo que, a partir de lo expuesto, es posible afirmar que los argumentos esgrimidos por la Corte IDH en la sentencia Artavia Murillo han redefinido el concepto de persona debilitando la protección del derecho fundamental a la vida que la Convención protege.

\section{3.- La persona para la Corte Interamericana de Derechos Humanos y posibles consecuencias}

De lo expuesto, en los acápites anteriores, podemos establecer lo siguiente respecto al tratamiento que le da la Corte a la persona humana:

La Corte hace un retroceso en cuanto a lo que tradicionalmente entendíamos por persona, yendo en contra de lo dispuesto en el preámbulo de la Convención que "señala que los derechos esenciales del hombre derivan de su naturaleza humana, no de atributos o características particulares, o percepciones de terceros" (De Jesús y Oviedo, 2016, p.48), lo cual pondría en tela de juicio la razón de ser de su existencia y de la obligatoriedad de sus pronunciamientos frente a los Estados americanos. El no reconocimiento del derecho a la vida de la persona desde su concepción, hace peligrar a todo el sistema jurídico de protección de los demás derechos que quedan relativizados, ya que "los derechos humanos así comprendidos no son autónomos, sino interdependientes, razón por la cual deben interpretarse unos a la luz y en coordinación con los restantes, de una forma sistemática, a fin de lograr un reforzamiento mutuo" (Silva, 2016, p.88). Sin embargo, en este caso, la Corte deja de lado esta interdependencia entre los derechos de la CADH para hacer una interpretación sesgada que permite su transgresión con apariencia de legalidad.

La interpretación restrictiva que hace la Corte del derecho a la vida del no nacido en sus primeros días y el quiebre de la identidad entre éste y su ser persona, respondería de acuerdo a la apreciación que hace la Dra. Di Pietro (2008), a una concepción antropológica subjetiva liberal, en la que el valor supremo es la libertad, entendida negativamente como autonomía sin responsabilidad, donde el criterio de bondad y licitud de toda acción es la elección del individuo en base a lo que siente, quiere, desea. Así entendida la libertad, la otra persona viene a ser solo un medio para conseguir nuestros deseos como en el caso de la utilización de técnicas de FIV, o puede configurarse como una traba de la que debo prescindir, legitimando conductas como la contracepción, el aborto, la eutanasia.

La Corte IDH deja vacío el concepto de persona al establecer que en uno de sus estadíos no es tal, en una clara actuación que sale de la lógica racional, ya que estaría afirmando que alguien que no es al inicio, luego es. Como afirma Spaemann (2000), "si el ser persona fuera un estado, podría surgir poco a poco. Pero si persona es alguien que pasa por diferentes estados, entonces los supone todos. (...) Las personas son o no son" (p.228). Lamentablemente, los jueces interamericanos dejaron ver en su mayoría, su marcado interés por superar esta lógica enmarcada en la realidad de las cosas, por lo que consideramos que su actuación responde a una ideología contraria a cualquier concepto "duro" que dé una 
orientación objetiva al contenido de los derechos, favoreciendo su relativización.

Además, la Corte IDH tendría una visión reduccionista de la persona. Para la Corte, la persona no tiene un sustrato primero, sino que está condicionada por la posesión y ejercicio de la autonomía, libertad y razón, que le dan el reconocimiento personal frente a otros seres humanos en los que dichas capacidades no han sido todavía desarrolladas; como sucede en el caso de las parejas demandantes de la FIV que para la Corte tendrían un claro derecho de protección a su vida familiar, frente a la nula protección que tendría la vida de los embriones. Esta visión reduccionista es muy peligrosa porque pone a la persona al nivel de las cosas, por lo que denotaría un gran desprecio por la vida más indefensa, que los jueces pretenden expandir a los países americanos miembros aun en contra de sus propios ordenamientos internos en favor de la persona.

La Corte ve a la persona como una función y no como al sujeto que puede realizar o no la función, cuando finalmente es el sujeto quien hace posible el desarrollo de las funciones sensitivas, intelectuales, autoconscientes, valorativas; quitándole erróneamente al embrión toda posibilidad de ser considerado persona (Palazzani, 2001).

Asimismo, para la Corte, no todos los seres humanos son iguales, yendo en clara contravención del contenido de la Convención que alude a la igualdad esencial entre todos los seres humanos para el disfrute de sus derechos; pues para la Corte, unos serían considerados personas y otros no, lo cual deviene en una clara acción discriminatoria (De Jesús y Oviedo, 2016).

Por último, la Corte estaría rechazando que "el ser de la persona es la vida del hombre" (Spaemann, 2000, p.236), con lo que pone en peligro no solo la protección al comienzo de la vida, sino también la vida en otros estadíos de la persona, especialmente en los momentos de mayor necesidad y atención, como la enfermedad o al final de vida, cuando es allí donde las personas demuestran su interioridad y su capacidad de amar a los quienes lo necesitan.

Por ello, solo en la identidad entre la vida humana, el ser humano y la persona, equilibrando sus dimensiones, físicas, antropológicas, éticas, jurídicas, se podrá cuidar y proteger a quien es la verdadera y principal razón de la existencia del carácter universal y absoluto de los derechos humanos: La persona.

\section{Conclusiones}

Solo a través la identificación entre el ser humano y la persona, en los diferentes ámbitos en los que se desarrolla y discurre, es posible lograr un equilibrio en cuanto a su concepto, ya que nos estaríamos refiriendo a una misma realidad; que a la vez debe ser el límite y criterio de actuación de la propia persona y de los demás frente a ella, de las comunidades, instituciones, de los Estados, a fin de que, de manera libre y segura, ejerza sus derechos y asuma deberes y se perfeccione como unidad corporal y espiritual.

Una sociedad que no es capaz de salvaguardar el bien de sus ciudadanos es una sociedad sombría, caótica; un sistema jurídico que no es capaz de dar lo debido a sus ciudadanos, especialmente los más débiles e indefensos, es injusto y por lo tanto se contradice a sí mismo, con el riesgo de desaparecer en un mar de leyes sin sentido, sin alma; un mundo así entendido es un lugar que la propia persona está llamada a iluminar con la verdad de su existencia y con la esencia de su ser persona única e irrepetible dentro de toda la Creación. 


\section{Bibliografía}

Amengual, G. (2015). La persona humana. El debate sobre su concepto. Madrid, España: Síntesis.

Bernal, C. (2010). Metodología de la investigación (3 ed.). Bogotá, Colombia Pearson Educación.

Chávez-Fernández J. (2014). Persona humana y derecho. Un diálogo con la filosofía jurídica de Javier Hervada. México DF, México: Porrúa.

Cianciardo J. (2016). La especificación del derecho a la vida del no nacido en el sistema interamericano de derechos humanos. Una aproximación desde el caso 'Artavia Murillo'. Dikaion, 25, (2), 160-189.

De Jesús, L. y Oviedo J. (2016). El caso Artavia Murillo y otros vs. Costa Rica ("fecundación in vitro"): la redefinición del derecho a la vida desde la concepción, reconocido en la Convención Americana. En M. Ramos-Kuri. (Ed.), Artavia Murillo vs. Costa Rica. Análisis crítico a la sentencia de la Corte Interamericana de Derechos Humanos en el fallo sobre fertilización in vitro (27-78). Querétaro, México: Centro de Investigación Social Avanzada.

De La Fuente, R. (2016). La persona como fons omnis iuris. Persona y Derecho, 74, 319338.

Díaz, A. (2013). La Corte Interamericana in vitro: comentarios sobre su proceso de toma de decisiones a propósito del caso Artavia.
Derecho Público Iberoamericano, (2), 303-345.

Di Pietro, M. (2008). Bioetica e famiglia [Bioética y familia]. Città del Vaticano: Lateran University Press.

Hernández, R. (2014). Metodología de la investigación (6 ed.). México DF, México: McGraw-Hill/Interamericana Editores.

Herranz, G. (2013). El embrión ficticio. Historia de un mito biológico. Madrid, España: Ediciones Palabra.

Hervada J. (1999). Introducción crítica al derecho natural. Piura, Perú: Universidad de Piura.

Melgar, A. (2016). El principio Pro Homine como clave hermenéutica de la interpretación de conformidad. El diálogo entre la Corte IDH y los tribunales peruanos. Arequipa, Perú: Universidad Católica San Pablo.

Palazzani, L. (1996). // concetto di persona tra bioetica e diritto [EI concepto de persona entre bioética y derecho] Torino, Italia: Giappichelli Editore.

Palazzani, L. (2001). Lo statuto giuridico dell'embrione umano [El estatuto jurídico del embrión humano]. Persona y Derecho, (44), 113-132.

Possenti, V. (2013). Concezione sostanziale e concezione funzionale della persona nella filosofía contemporánea [Concepción sustancial y concepción funcional de la persona en la filosofía contemporánea]. Espíritu, (146), 375-394.

RAMOS-KURI, M. El término concepción. Definición científica y errores de la Corte IDH al intentar redefinirla. En M. RamosKuri. (Ed.), Artavia Murillo vs. Costa Rica. 
Análisis crítico a la sentencia de la Corte Interamericana de Derechos Humanos en el fallo sobre fertilización in vitro (pp.217235). Querétaro, México: Centro de Investigación Social Avanzada.

Sgreccia, E. (2014). Manual de Bioética: Fundamentos y ética biomédica, Tomo I, (4 ed., 2 r). Madrid, España: Biblioteca de Autores Cristianos.

Silva, M. Los posibles efectos continentales del caso Artavia Murillo vs. Costa Rica a la luz del actual estado del derecho internacional de los derechos humanos. En M. Ramos-Kuri. (Ed.), Artavia Murillo vs. Costa Rica. Análisis crítico a la sentencia de la Corte Interamericana de Derechos Humanos en el fallo sobre fertilización in vitro (págs. 79-114). Querétaro, México: Centro de Investigación Social Avanzada.

Spaemann, R. (2000). Personas. Acerca de la distinción entre "algo" y "alguien". Navarra, España: EUNSA.
CONVENCION AMERICANA SOBRE DERECHOS HUMANOS (Pacto de San José). Recuperado de https://www.oas.org/dil/esp/tratados_b32 _convencion_americana_sobre_derechos_ humanos.htm

Declaraciones/Reservas/Denuncias/Retiros en referencia a la Convención Americana de Derechos Humanos. Recuperado de https://www.oas.org/dil/esp/tratados_B32_Convencion_Americana_sobre_Derech os_Humanos_firmas.htm

SENTENCIA DEL CASO ARTAVIA MURILLO $Y$ OTROS (FECUNDACIÓN IN VITRO) VS. COSTA RICA del 28 de noviembre del 2012 Serie C $N^{\circ}$ 257. Recuperado de http://www.corteidh.or.cr/docs/casos/artic ulos/seriec_257_esp.pdf

SENTENCIA DEL CASO ATALA RIFFO Y NIÑAS VS. CHILE del 12 de febrero del 2012 Serie C $\mathrm{N}^{\circ} \quad 239$. Recuperado de http://corteidh.or.cr/docs/casos/articulos/s eriec_239_esp.pdf 